ISSN: $2338-4794$

Vol.6. No. 2 Mei-Agustus 2018

\title{
DESKRIPSI KEMIMPINAN DAN PELATIHAN KERJA TERHADAP KINERJA ORGANISASI PT. TRANS OTO INTERNASIONAL
}

\author{
Bongsu Saragih *) \\ *) Dosen Program Studi Manajemen FE UNKRIS \\ Alamat: Kampus UNKRIS, Jatiwaringin Jakarta Timur \\ Email : bongsu.saragih@gmail.com
}

\begin{abstract}
A leader in an organization must have the ability to control or influence others. Other factors are expected to encourage the performance of each individual employee, namely job training. This study aims to find out how the description and conditions of leadership and job training influence organizational performance of PT. Trans Oto International both simultaneously and partially. Research samples were 50 respondents. The analysis technique uses multiple regression analysis. The analysis shows that leadership and training simultaneously affect organizational performance. This shows that leadership plays a role in improving organizational performance and better employee training can lead to higher organizational performance. Leadership partially affects organizational performance, which means that implementing better leadership in the company can improve organizational performance. Training partially affects organizational performance, which means that the better the training that employees follow can improve organizational performance.
\end{abstract}

Keywords: Leadership, Training, Organizational Performance

\section{PENDAHULUAN}

Dalam konteks pengembangan sumber daya manusia kinerja seorang karyawan dalam sebuah perusahaan sangat dibutuhkan untuk mencapai prestasi kerja bagi karyawan itu sendiri dan juga untuk keberhasilan perusahaan. Pengertian kinerja merupakan suatu hasil kerja yang dihasilkan oleh seorang karyawan untuk mencapai tujuan yang diharapkan. Menurut Rivai dan Basri (2005) pengertian kinerja adalah kesediaan seseorang atau kelompok orang untuk melakukan sesuatu kegiatan dan menyempurnakannya sesuai dengan tanggung jawab dengan hasil seperti yang diharapkan.

Dalam sebuah organisasi dibutuhkan seorang pemimpin yang bertugas untuk mengatur dan mengelola organisasi tersebut. Faktor kepemimpinan adalah suatu cara atau model yang diterapkan organisasi atau perusahaan dalam upaya pencapaian tujuan dan sasaran yang telah ditetapkan. Seorang pemimpin harus memiliki kemampuan untuk menguasai atau mempengaruhi orang lain untuk mencapai tujuan organisasi tersebut, atau yang lebih dikenal dengan kepemimpinan (Leadership). Menurut Terry (2005) kepemimpinan merupakan "Suatu hubungan yang ada didalam diri seseorang atau pemimpin dan mempengaruhi orang lain agar mau bekerja dengan sadar dalam hubungan tugas agar tercapainya sebuah tujuan yang diinginkan". Secara konseptual, pemimpin dilihat sebagai kata kunci yang menempati posisi krusial dalam sebuah organisasi. Sebuah oraganisasi takkan berjalan tanpa pemimpin, yang mendaulat orang-orang untuk bekerja dalam tim dan memberi kesempatan bagi mereka untuk berkembang. Pemimpin juga merupakan pembentuk visi, di mana ia dibantu oleh orang-orang di sekitarnya untuk menjalankan visinya tersebut.

Selain pemimpin suatu organisasi juga membutuhkan karyawan, karena merupakan salah satu aset penting bagi perkembangan perusahaan, faktor lain yang diharapkan dapat mendorong 
peningkatan kinerja dari setiap individu karyawan yaitu pelatihan kerja, untuk meningkatkan kualitas dan keterampilan kerja para karyawan, banyak perusahaan mengadakan pelatihan kerja. Biasanya pelatihan kerja dilakukan sebelum memulai kerja atau pada saat awal masuk bekerja yang tujuannya selain meningkatkan kualitas dan keterampilan kerja juga untuk menyiapkan karyawan agar lebih profesioanal. Menurut Kaswan (2011) pelatihan adalah proses untuk meningkatkan pengetahuan dan keterampilan karyawan.

PT.Trans Oto Internasional adalah salah satu perusahaan di Indonesia yang bergerak di bidang Otomotive Modern Workshop dengan outletnya yang bernama 1STATION, merupakan salah satu perusahaan dari kelompok usaha CT Corp (Chairul Tanjung Corporation). 1Station sudah bekerja sama dengan banyak merek untuk beberapa suku cadang seperti ban, oli, rem, dan beberapa aksesoris seperti wiper dan kaca film, juga memiliki layanan untuk perawatan kendaraan seperti Spooring, Balancing, Carwash sampai dengan Car Detailing dengan menggunakan alat-alat yang modern di setiap outletnya. Sumber daya Manusia yang ada di 1Station sudah mendapatkan keterampilan dan pengetahuan seputar mobil sebelum mulai bekerja, dengan di dukung 1Station Training Center, 1Station terus menghasilkan Sumber Daya Manusia yang berkualitas dan memiliki sikap profesionalisme yang tinggi.

\section{LANDASAN TEORI}

\section{Kepemimpinan}

Menurut C. Turney (1992) dalam Martinis Yamin dan Maisah (2010) mendefinisikan kepemimpinan sebagai suatu group proses yang dilakukan oleh seseorang dalam mengelola dan menginspirasikan sejumlah pekerjaan untuk mencapai tujuan organisasi melalui aplikasi teknik- teknik manajemen.

George R. Terry (Thoha, 2010) mengartikan bahwa Kepemimpinan adalah aktivitas untuk mempengaruhi orang-orang supaya diarahkan mencapai tujuan organisasi. Kepemimpinan meliputi proses mempengaruhi dalam menentukan tujuan organisasi, memotivasi perilaku pengikut untuk mencapai tujuan, mempengaruhi untuk memperbaiki kelompok dan budayanya.

\section{Pelatihan}

Sofyandi (2008) mengemukakan bahwa pelatihan adalah suatu usaha untuk meningkatkan pengertahuan dan kemampuan pegawai dalam melaksanakan pekerjaanya lebih efektif dan efisien. Notoatmodjo (2009) mendefinisikan pelatihan sebagai upaya untuk mengembangkan kemampuan intelektual dan kepribadian manusia. Pelatihan itu membantu karyawan dalam meningkatkan kemampuan dan keterampilan kerja yang dibutuhkan untuk menjadikan karyawan tersebut berhasil dalam pekerjaannya. Secara konkrit perubahan perilaku itu berbentuk peningkatan kemampuan dan sasaran karyawan yang bersangkutan. Kemampuan ini memerlukan pelatihan yang mencakup antara lain: kurikulum, oraganisasi pelatihan, peraturanperaturan, metode belajar dan tenaga pengajar atau pelatih itu sendiri.

\section{Kinerja Organisasi}

Kinerja merupakan hasil kerja secara kualitas dan kuantitas yang dapat dicapai oleh seorang pegawai dalam melaksanakan tugas sesuai dengan tanggung jawab yang diberikan kepadanya. Menurut Keban (2003), menyebutkan bahwa kinerja (performance) dalam organisasi didefinisikan sebagai tingkat pencapaian hasil "the degree of accomplishment " atau kinerja merupakan tingkat 
pencapaian tujuan organisasi secara berkesinambungan. Menurut Steers (2003) pengertian kinerja organisasi adalah tingkat yang menunjukan seberapa jauh pelaksanaan tugas dapat dijalankan secara aktual dan misi organisasi tercapai. Sedangkan menurut Mahsun (2006) kinerja adalah gambaran mengenai tingkat pencapaian pelaksanaan suatu kegiatan/program/kebijakan dalam mewujudkan sasaran, tujuan, misi, dan visi organisasi yang tertuang dalam strategic planning suatu organisasi.

Menurut Irawan (2000) Kinerja (performance) adalah hasil kerja yang konkrit, dapat diamati, dan dapat diukur. Sehingga kinerja merupakan hasil kerja yang dicapai oleh pegawai dalam pelaksanaan tugas yang berdasarkan ukuran dan waktu yang telah ditentukan.

\section{METODE PENELITIAN}

\section{Populasi dan Sampel}

Menurut Sugiyono (2008) Populasi adalah wilayah generalisasi terdiri atas obyek/subyek yang mempunyai kualitas dan karakteristik tertentu, ditetapkan oleh peneliti untuk dipelajari dan kemudian ditarik kesimpulan. Dalam penelitian ini populasi adalah seluruh pegawai dan karyawan PT. Trans Oto Internasioal sebanyak 100 pegawai, sedangkan sampel menurut Sugiyono (2008) adalah sebagian dari jumlah dan karakteristik yang dimiliki oleh populasi tersebut. Pada penelitian ini jumlah sampel sebanyak 50 karyawan pada PT. Trans Oto Internasional. Penentuan jumlah sample didasarkan pada pendapat dari Roscoe (1975) dikutip tahun (2000) yang menyatakan bahwa pertama, ukuran sample yang lebih besar dari 30 dan kurang dari 500 pada kebanyakan penelitian sudah mewakili. Kedua, jika sampel dibagi dalam subsample, maka setiap kategori diperlukan minimal 30 sampel. Metode pengambilan sampel yang digunakan adalah dengan menggunakan strafed random sampling yaitu sekelompok subyek secara acak berdasarkan ciri atau sifat tertentu yang dianggap memiliki hubungan erat dengan sifat-sifat populasi.

\section{HASIL PENELITIAN DAN PEMBAHASAN}

\author{
Hasil Penelitian \\ Uji Validitas
}


Tabel 1. Ringkasan Hasil Test Validitas Kuisioner

\begin{tabular}{|c|c|c|c|c|c|}
\hline Variabel & Item & $\begin{array}{l}\text { Koefisien } \\
\text { korelasi }\end{array}$ & $r$ tabel & Sig & Keterangan \\
\hline \multirow{8}{*}{$\begin{array}{l}\text { Kepemimpinan } \\
\qquad\left(\mathrm{X}_{1}\right)\end{array}$} & $\mathrm{X} 1.1 .1$ & 0,724 & 0,279 & 0,000 & Valid \\
\hline & $\mathrm{X} 1.1 .2$ & 0,767 & 0,279 & 0,000 & Valid \\
\hline & $\mathrm{X} 1.2 .1$ & 0,752 & 0,279 & 0,000 & Valid \\
\hline & $\mathrm{X} 1.2 .2$ & 0,764 & 0,279 & 0,000 & Valid \\
\hline & $\mathrm{X} 1.3 .1$ & 0,789 & 0,279 & 0,000 & Valid \\
\hline & $\mathrm{X} 1.3 .2$ & 0,752 & 0,279 & 0,000 & Valid \\
\hline & $\mathrm{X} 1.4 .1$ & 0,606 & 0,279 & 0,000 & Valid \\
\hline & X1.4.1 & 0,813 & 0,279 & 0,000 & Valid \\
\hline \multirow{12}{*}{ Pelatihan $\left(\mathrm{X}_{2}\right)$} & X2.1.1 & 0,710 & 0,279 & 0,000 & Valid \\
\hline & $\mathrm{X} 2.1 .2$ & 0,781 & 0,279 & 0,000 & Valid \\
\hline & $\mathrm{X} 2.2 .1$ & 0,498 & 0,279 & 0,000 & Valid \\
\hline & $\mathrm{X} 2.2 .2$ & 0,463 & 0,279 & 0,001 & Valid \\
\hline & $\mathrm{X} 2.3 .1$ & 0,595 & 0,279 & 0,000 & Valid \\
\hline & $\mathrm{X} 2.3 .2$ & 0,617 & 0,279 & 0,000 & Valid \\
\hline & $\mathrm{X} 2.4 .1$ & 0,766 & 0,279 & 0,000 & Valid \\
\hline & X2.4.2 & 0,610 & 0,279 & 0,000 & Valid \\
\hline & X2.5.1 & 0,477 & 0,279 & 0,000 & Valid \\
\hline & X2.5.2 & 0,468 & 0,279 & 0,000 & Valid \\
\hline & X2.6.1 & 0,594 & 0,279 & 0,000 & Valid \\
\hline & $\mathrm{X} 2.6 .2$ & 0,753 & 0,279 & 0,000 & Valid \\
\hline \multirow{10}{*}{$\begin{array}{c}\text { Kinerja organisasi } \\
\text { (Y) }\end{array}$} & Y1.1.1 & 0,642 & 0,279 & 0,000 & Valid \\
\hline & $\mathrm{Y} 1.1 .2$ & 0,779 & 0,279 & 0,000 & Valid \\
\hline & Y1.2.1 & 0,407 & 0,279 & 0,003 & Valid \\
\hline & $\mathrm{Y} 1.2 .2$ & 0,808 & 0,279 & 0,000 & Valid \\
\hline & Y1.3.1 & 0,609 & 0,279 & 0,000 & Valid \\
\hline & Y1.3.2 & 0,695 & 0,279 & 0,000 & Valid \\
\hline & Y1.4.1 & 0,659 & 0,279 & 0,000 & Valid \\
\hline & Y1.4.2 & 0,656 & 0,279 & 0,000 & Valid \\
\hline & Y1.5.1 & 0,760 & 0,279 & 0,000 & Valid \\
\hline & Y1.5.2 & 0,423 & 0,279 & 0,002 & Valid \\
\hline
\end{tabular}

Sumber : Data primer diolah, 2018.

Dari tabel diatas diungkapkan bahwa hasil uji validitas diungkapkan bahwa nilai $r$ tabel product moment pada $\alpha=0,05$ dan $\mathrm{n}=50$ sebesar 0,279. Dari pengolahan data terlihat dari 38 indikator yang diuji, semua indikator memiliki nilai koefisien korelasi positif dan lebih besar dari $r$ tabel, serta probabilitasnya lebih kecil dari $\alpha=5 \%$, artinya ada hubungan yang signifikan antara skor masing-masing indikator dengan skor total. Korelasi yang signifikan menunjukkan bahwa indikator memang benar-benar dapat digunakan untuk mengukur variabel yang akan diukur, dengan kata lain instrumen yang digunakan valid dengan demikian dapat dipakai dalam penelitian. 


\section{Uji Reliabilitas}

Tabel 2. Nilai Koefisien Reliabilitas Variabel

\begin{tabular}{lcc}
\hline \multicolumn{1}{c}{ Variabel } & Koefisien Reliabilitas & Keterangan \\
\hline Kepemimpinan $\left(\mathrm{X}_{1}\right)$ & 0,886 & Reliabel \\
Pelatihan $\left(\mathrm{X}_{2}\right)$ & 0,847 & Reliabel \\
Kinerja organisasi $(\mathrm{Y})$ & 0,844 & Reliabel \\
\hline
\end{tabular}

Sumber : Data primer diolah.

Dari pengolahan data di atas, dapat dilihat bahwa semua variabel mempunyai koefisien reliabilitas lebih besar dari 0,60, jadi berdasarkan uji reliabilitas, instrumen yang ada layak untuk dipergunakan.

\section{Uji hipotesis}

1. Untuk menguji hipotesis pertama yang menyatakan bahwa ada pengaruh secara simultan antara kepemimpinan dan pelatihan kerja terhadap kinerja karyawan PT. Trans Oto Internasional, dengan menggunakan uji F. Dari hasil perhitungan analisis regresi berganda dengan SPSS diperoleh $F_{\text {hitung }}$ sebesar 121,155, sedangkan $F_{\text {tabel }}$ pada $\alpha=5 \%, \mathrm{df}_{1}=2$, dan $\mathrm{df}_{2}=$ 47 sebesar 2,95; hal ini berarti $F_{\text {hitung }}>$ $\mathrm{F}_{\text {tabel }}(121,155>2,95)$ sedangkan nilai probabilitasnya lebih kecil dari $\alpha=$ $0,05(0,000<0,05)$, maka Ho ditolak dan $\mathrm{Ha}$ diterima yang berarti bahwa variabel bebas : Kepemimpinan dan Pelatihan secara simultan berpengaruh signifikan terhadap kinerja organisasi. Dengan demikian hipotesis pertama secara statistik teruji.

2. Untuk menguji hipotesis kedua yang menyatakan ada pengaruh secara parsial antara kepemimpinan dengan kinerja karyawan PT. Trans Oto Internasional, dengan menggunakan uji t. Hasil analisis regresi diperoleh nilai $t_{\text {hitung }}=6,215$ sedangkan nilai $t_{\text {tabel }}$ $=2,048$ sehingga $t_{\text {hitung }}>t_{\text {tabel }}$ atau nilai signifikansi $0,000<0,05$ jadi Ho ditolak atau Ha diterima, dan terbukti variabel Kepemimpinan (X1) berpengaruh signifikan terhadap Kinerja organisasi (Y). Dengan demikian hipotesis kedua secara statistik teruji.

3. Untuk menguji hipotesis ketiga yang menyatakan ada pengaruh secara parsial antara pelatihan kerja dengan kinerja karyawan PT. Trans Oto Internasional, dengan menggunakan uji t. Hasil analisis regresi diperoleh nilai $t_{\text {hitung }}=3,919$ sedangkan nilai $t_{\text {tabel }}$ $=2,048$ sehingga $t_{\text {hitung }}>t_{\text {tabel }}$ atau nilai signifikansi $0,000<0,05$ jadi Ho ditolak atau Ha diterima, dan terbukti variabel pelatihan (X2) berpengaruh signifikan terhadap Kinerja organisasi (Y). Dengan demikian hipotesis ketiga secara statistik teruji.

\section{KESIMPULAN DAN SARAN}

\section{Kesimpulan}

Berdasarkan pembahasan di atas dapat disimpulkan sebagai berikut: 1). Hipotesis pertama yaitu ada pengaruh secara simultan antara kepemimpinan dan pelatihan kerja terhadap kinerja karyawan PT. Trans Oto Internasional dibuktikan dan diterima. Kepemimpinan dibentuk dari pengarahan, komunikasi, pengambilan keputusan dan motivasi. Kontribusi utama pembentukan Kepemimpinan adalah pengarahan tercermin dari Pimpinan menginformasikan kebijakan dan prosedur kepada bawahan. Pelatihan dibentuk instruktur, peserta, materi, metode, tujuan dan sasaran. Kontribusi utama pembentukan pelatihan adalah keadilan tercermin dari Pelatihan 
dilakukan secara adil. Kinerja organisasi dibentuk dari perspektif keuangan, perspektif pelanggan, perspektif proses bisnis internal dan perspektif proses belajar dan berkembang. Kontribusi utama pembentukan kinerja organisasi adalah perspektif keuangan tercermin dari Target tiap tri wulan PT. Trans Oto Internasional senantiasa dapat tercapai. 2). Hipotesis kedua yaitu ada pengaruh secara parsial antara kepemimpinan dengan kinerja karyawan PT. Trans Oto Internasional diterima dan dibuktikan. Pernyataan ini mengartikan bahwa semakin baik penerapan kepemimpinan dalam perusahaan dapat meningkatkan kinerja organisasi. 3). Hipotesis ketiga yaitu ada pengaruh secara parsial antara pelatihan kerja dengan kinerja karyawan PT. Trans Oto Internasional. Pernyataan ini mengartikan bahwa semakin baik pelatihan yang diikuti oleh karywan dapat meningkatkan kinerja organisasi.

\section{Saran}

Sehubungan dengan hal-hal yang telah diuraikan di atas maka dapat diberikan saran-saran sebagai berikut : 1). Sebaiknya pimpinan mau mendengarkan ide-ide dan masukan dari karyawan, agar kinerja organisasi dapat meningkatkan kinerja organisasi. 2). Semua karyawan diberi kesempatan yang sama untuk mengikuti pelatihan, agar dapat meningkatkan ketrampilan dan kemampuan sehingga berdampak pada peningkatan kinerja organisasi. 3). Bagi peneliti selanjutnya, diharapkan dapat melakukan pengembangan penelitian dengan menggunakan variabel bebas yang lain, sehingga dapat memberikan pengaruh lebih baik lagi terhadap kinerja organisasi.

\section{DAFTAR PUSTAKA}

Arikunto, Suharsimi. 2002. Prosedur Penelitian - Suatu Pendekatan Praktek, Cetakan Kedua Belas
(Edisi Revisi V). Jakarta: PT. Rineka Cipta.

Dessler, Gary. 2009. Manajemen Sumber Daya Manusia, Jakarta :Edisi Kesepuluh.

Gudono. 2010. Teori Organisasi. Edisi 1, Pensil Press, Daerah Istimewa Yogyakarta.

Irawan. 2000. Manajemen Pemasaran Modern Edisi Kedua. Yogyakarta : Liberty

Kaswan. 2012. Manajemen Sumber Daya Manusia untuk Keunggulan Bersaing Organisasi. Graha Ilmu, Yogyakarta

Keban, T. Yeremias. 2003. Enam Dimensi Strategis Administrasi Publik, Konsep, Teori dan Isu. Gava Media. Yogyakarta

Lubis, Khairul Akhir. 2008 Pengaruh Pelatihan dan Motivasi Kerja Terhadap Kinerja Karyawan PT.Perkebunan Nusantara IV (Persero) Medan. Skripsi. Pascasarjana Universitas Sumatera Utara Medan.

Mahmudi. 2010. Manajemen Kinerja Sektor Publik, UPP STIM YKPN, Yogyakarta.

Mahsun, M. 2006. Pengukuran Kinerja Sektor Publik. Yogyakarta: BPFE.

Mangkunegara, Anwar Prabu 2006. Evaluasi Kinerja Sumber Daya. Manusia. Jakarta: Refika Aditama.

Martinis Yamin dan Maisah. 2010. Standarisasi Kinerja Guru. Cetakan 1, Jakarta: Gaung.

Mathis.L.Robert dan Jackson.H.John. 2006. Manajemen Sumber Daya Manusia. Buku kedua. Jakarta.

Notoatmodjo, $\quad$ Soekidjo, 2009. Pengembangan Sumber Daya Manusia. Cetakan Ketiga. Jakarta : Rineka Cipta.

Purwanti, Heni. 2015. Pengaruh Kepemimpinan Motivasi dan Pelatihan Terhadap Kinerja Karyawan Toko Prima Srandakan. 
Skripsi. Fakultas Ekonomi Universitas PGRI Yogyakarta

Riduwan. 2012. Skala Pengukuran Variabel-variabel Penelitian. Bandung. Alfabeta.

Rivai, V. dan Basri, A. F. M. 2005. Performance Appraisal. Jakarta: PT Raja. Grafindo Persada.

Sedarmayanti. 2010. Birokrasi dan Manajemen Pegawai Negeri Sipil: Reformasi Birokrasi dan Manajemen Pegawai Negeri Sipil. Bandung: Refika Aditama. . 2009. Manajemen Sumber Daya Manusia dan Produktivitas Kerja. Cetakan Ketiga. Bandung: Mandar Maju.

Septianto, Dwi. (2010). "Pengaruh Lingkungan Kerja dan Stress Kerja Terhadap Kinerja Karyawan Studi Pada PT. Pataya Semarang", Skripsi. Universitas Diponegoro, Semarang.

Soekarso. 2010. Teori Kepemimpinan. Jakarta: Mitra Wacana Media.

Soeratno. 2000. Ekonomi Mikro Pengantar. Edisi Ke-1, STIE YKPN, Yogyakarta.
Sofyandi, Herman. 2008. Manajemen Rekrutmen dan Training. Bandung: Fakultas Bisnis dan Manajemen Universitas Widyatama.

Steers, Richard M. 2003. Efektivitas Organisasi, Erlangga, Jakarta.

Sugiyono. 2008. Metode Penelitian Kunatitatif Kualitatif dan $R \& D$. Bandung Alfabeta. . 2010. Metode Penelitian Kuantitatif Kualitatif dan $R \& D$. Penerbit CV Alfabeta, Bandung. . 2012. Metode Penelitian Kuantitatif Kualitatif dan $R \& D$. Bandung: Alfabeta.

Terry, George. 2005. Prinsip-prinsip Manajemen PT. Bumi Aksara. Jakarta.

Thoha, Miftah, 2010. Kepemimpinan Dalam Manajeme., Jakarta : Rajawali Pers.

Tika, Moh. Pabundu. 2010. Budaya Organisasi dan Peningkatan Kinerja Perusahaan. Cetakan Ketiga. Jakarta: Bumi Aksara. 